\title{
Synthesis, Characterization, and Catalytic Application of Highly Ordered Mesoporous Alumina-Carbon Nanocomposites
}

\author{
Jinming $\mathrm{Xu}^{1,2}$, Aiqin Wang ${ }^{1}$, Xiaodong Wang ${ }^{1}$, Dangsheng $\mathrm{Su}^{3}$, and Tao Zhang ${ }^{1}(\bowtie)$ \\ ${ }^{1}$ State Key Laboratory of Catalysis, Dalian Institute of Chemical Physics, Chinese Academy of Sciences, 457 Zhongshan Road, Dalian \\ 116023, China \\ ${ }^{2}$ Graduate University of the Chinese Academy of Sciences, Beijing 100049, China \\ ${ }^{3}$ Fritz-Haber Institute of the Max Planck Society, Berlin D-14195, Germany \\ Received: 16 July 2010 / Revised: 16 August 2010 / Accepted: 30 August 2010 \\ (C) The Author(s) 2010. This article is published with open access at Springerlink.com
}

\begin{abstract}
Highly ordered mesoporous carbon-alumina nanocomposites (OMCA) have been synthesized for the first time by a multi-component co-assembly method followed by pyrolysis at high temperatures. In this synthesis, resol phenol-formaldehyde resin ( $\mathrm{PF}$ resin) and alumina sol were respectively used as the carbon and alumina precursors and triblock copolymer Pluronic F127 as the template. $\mathrm{N}_{2}$-adsorption measurements, $\mathrm{X}$-ray diffraction, and transmission electron microscopy revealed that, with an increase of the alumina content in the nanocomposite from 11 to $48 \mathrm{wt} . \%$, the pore size increased from 2.9 to $5.0 \mathrm{~nm}$ while the ordered mesoporous structure was retained. Further increasing the alumina content to $53 \mathrm{wt} . \%$ resulted in wormhole-like structures, although the pore size distribution was still narrow. The nanocomposite walls are composed of continuous carbon and amorphous alumina, which allows the ordered mesostructure to be well preserved even after the removal of alumina by HF etching or the removal of carbon by calcination in air. The OMCA nanocomposites exhibited good thermostability below $1000{ }^{\circ} \mathrm{C}$; at higher temperatures the ordered mesostructure partially collapsed, associated with a phase transformation from amorphous alumina into $\gamma-\mathrm{Al}_{2} \mathrm{O}_{3}$. OMCA-supported Pt catalysts exhibited excellent performance in the one-pot transformation of cellulose into hexitols thanks to the unique surface properties of the nanocomposite.
\end{abstract}

\section{KEYWORDS}

Nanocomposite, mesoporous, alumina, carbon, cellulose

\section{Introduction}

The chemical transformation of cellulose into valuable chemicals, such as polyols, is currently regarded as an important way to produce chemicals from renewable resources and thus, reduce our dependence on fossil resources [1-6]. Fukuoka et al. [1] have developed an environmentally friendly process for the direct conversion of cellulose into sugar alcohols by combining the hydrolysis of cellulose in hot water with the hydrogenation of glucose. In this attractive process, the key issue is to develop a highly active and selective catalyst because the yield of the target product is critically dependent on the properties of the catalyst. For example, Pt supported on a variety of materials including alumina, silica, and zeolites

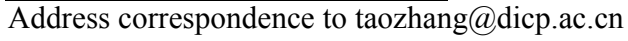


gave quite different catalytic performances in the conversion of cellulose; $\mathrm{Pt} / \mathrm{Al}_{2} \mathrm{O}_{3}$ was found to be the most active catalyst, giving a yield of hexitols (containing sorbitol and mannitol) as high as 31\% [1]. On the other hand, when the reaction was carried out at a higher temperature, $\mathrm{Ru}$ /activated carbon was found to be a more selective and robust catalyst, giving a yield of hexitols of up to 39\% [2]. Actually, carbon materials are among the best choices as a support for noble metal catalysts due to their excellent stability in hot water and the easy recovery of the noble metals. However, a carbon surface is generally thought to have a weak interaction with the metal particles supported on it, which is evidenced by the tendency of metal particles to sinter on carbon supports [7]. In contrast to carbon, an alumina surface has a strong interaction with metal species and therefore can promote the formation of highly dispersed metal particles $[8,9]$. Given the different, even completely opposite, surface properties of carbon and alumina, it would be very interesting to create a new material which combines the surface properties of both carbon and alumina. Taking into account that the metal-support interaction plays a central role in determining the catalytic performance, one can imagine that such carbon-alumina composites may give rise complementary, even unexpected, properties which are desirable in catalysis.

Recently, nanocomposite materials with ordered mesoporous structures have attracted much attention [10-12]. The uniform pore sizes and large surface areas, as well as the unique features derived from combining two or more components together on the nanoscale, offer many possibilities for tuning the catalytic activity and selectivity when the nanocomposites are used as catalysts or catalyst supports. In order to fabricate ordered mesoporous nanocomposites, a multi-component co-assembly synthesis strategy has been developed [13]. In this method, two or more components are homogeneously dispersed in the walls of the mesoporous structure, thus, no pore blockage occurs. Moreover, the framework composition can be continuously tuned over a wide range, creating a spectrum of materials with the same mesostructure but very different framework compositions, just like zeolites. In particular, this multi-component co-assembly process has shown great success in the synthesis of carbon-based nanocomposites with ordered mesostructures [13-29]. For example, Zhao et al. synthesized carbon- $\mathrm{SiO}_{2}$ nanocomposites with interpenetrating networks using an evaporation-induced triconstituent co-assembly of resol phenol-formaldehyde resin (PF resin) oligomer, prehydrolyzed tetraethyl orthosilicate (TEOS), and triblock copolymer Pluronic F127, followed by carbonization [13]. The resulting nanocomposites not only possess highly ordered pore structures and large surface areas, but can also have varied pore walls compositions, thus, giving rise to tunable surface properties from hydrophilic to hydrophobic. Such nanocomposites show great advantages over a single component, both as a catalyst support and as corrosion-resistant electrodes [15]. Using the same triconstituent co-assembly strategy, Zhao et al. also fabricated highly ordered mesoporous $\mathrm{C}-\mathrm{TiO}_{2}$ and $\mathrm{C}-\mathrm{TiC}$ nanocomposites $[18,21]$. However, different from the $\mathrm{C}-\mathrm{SiO}_{2}$ nanocomposites where the silica content can be varied from zero to infinity, the $\mathrm{TiO}_{2}$ content in the $\mathrm{C}-\mathrm{TiO}_{2}$ nanocomposite can be adjusted only over a limited range, outside which the mesostructure collapses. This suggests that the success of multi-component co-assembly depends strongly on the chemical nature of the individual components and the interaction between them. In other words, in order to successfully co-assemble the three components, the hydrolysis of each precursor must be adjusted to match them. Although the strategy for multicomponent co-assembly is simple and similar to that for surfactant-induced self-assembly of silicates, the successful synthesis of highly ordered mesoporous nanocomposites using this strategy is still a challenge in many cases, in particular when the hydrolysis and condensation of one component is difficult to control.

Alumina is such a case. Since the hydrolysis and condensation of aluminum is very complex and difficult to control $[30,31]$, the synthesis of carbonalumina nanocomposites with an ordered mesoporous structure presents a challenge. Previously, Górka and Jaroniec [16] reported a facile method for incorporation of alumina nanoparticles into mesoporous carbon by using an alumina colloid as the aluminum source. However, due to the relatively large particle size $(50 \mathrm{~nm})$ of the alumina precursor, the two components, aluminum, and carbon, were not 
homogeneously mixed on a molecular level. Recently, they also reported the synthesis of an alumina-carbon composite by using aluminum isopropoxide as the aluminum source under different acidic conditions [19]. However, the resulting composite showed alumina nanoparticles of about $17 \mathrm{~nm}$ embedded into the mesoporous carbon, rather than a really homogeneously mixed nanocomposite. Herein, we report the synthesis of a new nanocomposite material composed of carbon and alumina, by means of multi-component co-assembly of an alumina sol, resol, and triblock copolymer Pluronic F127. In this work, we used citric acid as a good coordination agent to regulate the hydrolysis-condensation of aluminum species [30, 31]. The resulting carbon-alumina nanocomposites possess highly ordered mesoporous structures, and the alumina content in the nanocomposite can be continuously tuned from 10 to $53 \mathrm{wt}$.\%. In contrast to previously reported carbon-alumina composites, the walls of our ordered mesoporous carbon-alumina nanocomposite are composed of homogenously distributed carbon and alumina. Moreover, the new nanocomposite is a good support for Pt catalysts, which exhibit high catalytic activities for cellulose conversion into hexitols.

\section{Experimental}

Pluronic F127, a block copolymer of ethylene oxide (EO) and propylene oxide (PO) $\left(M_{\mathrm{av}}=12,600, \mathrm{EO}_{106} \mathrm{PO}_{70} \mathrm{EO}_{106}\right)$ was purchased from Sigma-Aldrich. Aluminum iso-propoxide and citric acid were purchased from Sinopharm Chemical Reagent. $\mathrm{HCl}$ and $\mathrm{NaOH}$ were purchased from Tianjin Windship Chemistry Technological Corp. Phenol and formaldehyde (37 wt.\%) were purchased from Tianjin Kermel Chemical Reagent Co. Ltd. Ethanol was purchased from Tianjin Hengxing Chemical Preparation Corp. Aluminum iso-propoxide was purified by extraction with cyclohexane. All other chemicals were used as received without further purification. Deionized water was used in all experiments.

\subsection{Preparation of precursors}

The resol precursor was prepared according to the Ref. [32]. In a typical synthesis, $30.50 \mathrm{~g}$ of phenol was mixed with $6.50 \mathrm{~g}$ of $20 \mathrm{wt} . \% \mathrm{NaOH}$ aqueous solution under stirring, and $50.00 \mathrm{~g}$ of formaldehyde solution (37 wt.\%) was then added. The resulting transparent solution was stirred at $75{ }^{\circ} \mathrm{C}$ for $1 \mathrm{~h}$, cooled to room temperature, and the $\mathrm{pH}$ was then adjusted to about 7.0 by $2.0 \mathrm{~mol} / \mathrm{L} \mathrm{HCl}$. After water was removed by vacuum distillation, the mixture was redispersed in $200 \mathrm{~g}$ of ethanol. The $\mathrm{NaCl}$ precipitate was removed by filtration, and the filtrate, the resol precursor with a concentration of $20 \mathrm{wt} . \%$ in ethanol, was collected.

To prepare the alumina sol, $4.5 \mathrm{~mL}$ of $37 \mathrm{wt} . \% \mathrm{HCl}$ and $3.15 \mathrm{~g}$ of citric acid was dissolved in $36 \mathrm{~g}$ of ethanol, to which $6.12 \mathrm{~g}$ of aluminum iso-propoxide was added. The molar ratio of $\mathrm{Al}\left(\mathrm{OPr}^{\mathrm{i}}\right)_{3} /$ citric acid $/ \mathrm{HCl} / \mathrm{H}_{2} \mathrm{O} / \mathrm{EtOH}$ was fixed at 1/0.5/1.8/6.2/26. The resulting solution was stirred for $5 \mathrm{~h}$ to obtain transparent alumina sol.

\subsection{Preparation of ordered mesoporous alumina- carbon nanocomposites}

The ordered mesoporous alumina-carbon nanocomposites were synthesized via the co-assembly of resol, alumina sol, and copolymer Pluronic F127. In a typical procedure, $1.25 \mathrm{~g}$ of triblock copolymer F127 was dissolved in $8.43 \mathrm{~g}$ of alumina sol (containing $1.02 \mathrm{~g}$ of aluminum iso-propoxide) at $40{ }^{\circ} \mathrm{C}$, to which $2.0 \mathrm{~g}$ of the resol precursor solution (containing $0.4 \mathrm{~g}$ of resol) was added under stirring. After being stirred for $30 \mathrm{~min}$, the solution was cast onto a glass substrate $\left(25 \times 40 \mathrm{~cm}^{2}\right)$ and then transferred into an oven for evaporation-induced self-assembly (EISA) under a specific heating program: $35^{\circ} \mathrm{C}$ for $2 \mathrm{~h}, 60^{\circ} \mathrm{C}$ for $40 \mathrm{~h}$, and $100{ }^{\circ} \mathrm{C}$ for $24 \mathrm{~h}$. The as-made transparent films were scraped from the glass substrate, cut into small pieces and pyrolyzed in a tubular furnace at $800{ }^{\circ} \mathrm{C}$ for $3 \mathrm{~h}$ in $\mathrm{N}_{2}$ flow. The heating rate was $1^{\circ} \mathrm{C} / \mathrm{min}$ below $600{ }^{\circ} \mathrm{C}$ and $2{ }^{\circ} \mathrm{C} / \mathrm{min}$ above $600{ }^{\circ} \mathrm{C}$. Nanocomposites with different alumina contents from 11 to $53 \mathrm{wt} . \%$ were synthesized by varying the mass ratio of the two precursors and the amount of F127, as described in Table 1, and the resulting nanocomposites are denoted as OMCA- $x$, where OMCA refers to ordered mesoporous carbon-alumina and $x$ represents the mass percentage of the alumina in the nanocomposite, which was determined by thermogravimetric (TG) analysis. The OMCA- $x$ was calcined in air at $550{ }^{\circ} \mathrm{C}$ 
Table 1 Preparation conditions and compositions of the carbonalumina nanocomposites

\begin{tabular}{|c|c|c|c|c|c|}
\hline Sample & $\begin{array}{l}\text { Alumina } \\
\text { sol }(g)^{a}\end{array}$ & $\begin{array}{l}\text { Resol } \\
(\mathrm{g})^{\mathrm{b}}\end{array}$ & $\begin{array}{c}\text { F127 } \\
(\mathrm{g})\end{array}$ & $\begin{array}{l}\mathrm{C}-\mathrm{O}-\mathrm{H} \\
\text { (wt.\%) }^{\mathrm{c}}\end{array}$ & $\begin{array}{l}\text { Alumina } \\
\left(\text { wt.\%) }{ }^{\mathrm{c}}\right.\end{array}$ \\
\hline OMCA-11 & 1.69 & 5.75 & 1.20 & 88.6 & 11.4 \\
\hline OMCA-21 & 3.37 & 5.00 & 1.00 & 79.4 & 20.6 \\
\hline OMCA-33 & 6.74 & 3.30 & 1.50 & 66.8 & 33.2 \\
\hline OMCA-48 & 8.43 & 2.00 & 1.25 & 52.0 & 48.0 \\
\hline OMCA-53 & 16.86 & 1.60 & 2.00 & 46.7 & 53.3 \\
\hline
\end{tabular}

${ }^{\mathrm{a}}$ The concentration of $\mathrm{Al}$ in the alumina sol was $0.593 \mathrm{mmol} / \mathrm{g}$.

${ }^{\mathrm{b}}$ The concentration of resol was $20 \mathrm{wt} . \%$.

${ }^{\mathrm{c}} \mathrm{C}-\mathrm{O}-\mathrm{H} \%$ and alumina\% are the mass percentages in the mesoporous carbon-alumina nanocomposites, determined by TG analysis.

for $3 \mathrm{~h}$ to burn off the carbon and obtain ordered mesoporous alumina (denoted as OMA-x). The alumina in the nanocomposites was removed by immersing the OMCA- $x$ in $20 \%$ HF for $6 \mathrm{~h}$ and the etching procedure was repeated twice to obtain ordered mesoporous carbons (denoted as OMC- $x$ ).

\subsection{Preparation of Pt catalysts}

The nanocomposite OMCA-48 and its derivatives OMC-48 and OMA-48 were used as supports for Pt catalysts. Pt was loaded on the supports by impregnation with an ethanol solution of $\mathrm{H}_{2} \mathrm{PtCl}_{6}$. After drying at room temperature for $24 \mathrm{~h}$, and then $120^{\circ} \mathrm{C}$ for $12 \mathrm{~h}$ and finally reducing in $\mathrm{H}_{2}$ at $400{ }^{\circ} \mathrm{C}$ for $1 \mathrm{~h}$, the catalysts with a Pt content of $4 \mathrm{wt} . \%$ were obtained and denoted as Pt/OMCA-48, Pt/OMC-48, and Pt/OMA-48, respectively. Before exposure to air, the as-prepared catalysts were passivated in a flow of $1 \% \mathrm{O}_{2} / \mathrm{N}_{2}$ for $5 \mathrm{~h}$.

\subsection{Characterization}

Nitrogen adsorption-desorption isotherms were obtained on a Micromeritics ASAP 2010 apparatus at $-196{ }^{\circ} \mathrm{C}$. Prior to the measurements, the samples were degassed at $200{ }^{\circ} \mathrm{C}$ for $6 \mathrm{~h}$. The Brunauer-EmmettTeller (BET) method was used to calculate the specific surface areas. The pore size distributions and the mesopore volumes $\left(V_{\text {meso }}\right)$ were derived from the adsorption branches of the isotherms using the Barrett-Joyner-Halenda (BJH) method. The total pore volumes, $V_{\mathrm{p}}$, were estimated from the adsorption branches at a relative pressure $\left(P / P_{0}\right)$ of 0.998 . The micropore volume, $V_{\text {micro, }}$ was determined according to the $t$-plot method. The $t$ values were calculated as a function of the relative pressure using the de Boer equation, $t=\left[13.9900 /\left(0.0340-\log \left(P / P_{0}\right)\right)\right]^{0.500}$. $V_{\text {micro }}$ was obtained using the equation $V_{\mathrm{m}}=0.001547 Y_{\mathrm{INT}}$, where $Y_{\text {INT }}$ represents the $Y$ intercept in the $t$ plot. Powder $X$-ray diffraction (XRD) patterns were recorded with a PANalytical X'Pert PRO powder X-ray diffractometer using $\mathrm{Cu} \mathrm{K \alpha}$ radiation. Transmission electron microscopy (TEM) was conducted on a Tecnai $G^{2}$ Spirit electronic microscope with an accelerating voltage of $120 \mathrm{kV}$, while high-resolution transmission electron microscopy (HRTEM) was performed on a Tecnai $G^{2}$ F30 S-Twin transmission electron microscope operating at $300 \mathrm{kV}$. The samples for TEM and HRTEM observations were ultrasonically dispersed in ethanol and dropped onto a holey carbon film on a $\mathrm{Cu}$ grid. TG and differential thermoanalysis (DTA) were performed on a Setaram Setsys 16/18 thermoanalyzer with a heating rate of $10{ }^{\circ} \mathrm{C} / \mathrm{min}$ in air flow. The $\mathrm{H}_{2}$ uptakes of supported Pt catalysts were measured by the $\mathrm{H}_{2}$ pulse chemisorption method using a Micromeritics 2920 AutoChem II apparatus. Before $\mathrm{H}_{2}$ chemisorption was performed, the catalyst samples were pretreated with $\mathrm{H}_{2}$ at $400{ }^{\circ} \mathrm{C}$ for $1 \mathrm{~h}$ and then purged with Ar.

\subsection{Catalytic reaction}

The supported Pt catalysts were evaluated for cellulose conversion in aqueous solution under a pressure of $6 \mathrm{MPa}$ [3]. In a typical run, $0.5 \mathrm{~g}$ of cellulose (Merck, microcrystalline), $0.15 \mathrm{~g}$ of a catalyst, and $50 \mathrm{~mL}$ of deionized water were put into a stainless-steel autoclave (Parr Instrument Company, $100 \mathrm{~mL}$ ) and stirred at $1000 \mathrm{r} / \mathrm{min}$, and the reaction was carried out at $245^{\circ} \mathrm{C}$ for $30 \mathrm{~min}$. The initial $\mathrm{H}_{2}$ pressure was $6 \mathrm{MPa}$, and it increased to about $13 \mathrm{MPa}$ at $245^{\circ} \mathrm{C}$. After the reaction, the liquid-phase products were analyzed by highperformance liquid chromatography (HPLC) and electrospray ionization-mass spectrometry (ESI-MS). Cellulose conversions were determined based on the change of cellulose mass before and after the reaction. The yield of polyols was calculated from the equation: yield $(\%)=($ mass of polyol in the products $) /$ (mass of cellulose put into the reactor) $\times 100 \%$.

\section{Results and discussion}

The mesoporous carbon-alumina nanocomposites 
were synthesized by co-assembly of resol, alumina sol, and triblock copolymer Pluronic F127. Compared with silica, the hydrolysis of aluminium is faster and more difficult to control. Previously, we found that hydroxycarboxylic acids (HCA) can complex Al cations and even induce the arrangement of $\mathrm{AlOOH}$ particles, just like a structure-directing agent [30]. Following our work, Yan et al. used citric acid as an inhibitor for the hydrolysis-condensation process of aluminium species [31]. Via evaporation-induced co-assembly of triblock copolymer and Al-citrate complex, they produced highly ordered mesoporous $\gamma$-alumina. From these previous results one can see that citric acid is a good coordination agent for regulating the hydrolysis-condensation of aluminum species. Therefore, in the present work, we employed citric acid as the complexing agent to control the hydrolysis of aluminium and obtained a stable alumina sol. Then we employed this alumina sol as the alumina precursor, resol as the carbon precursor, and F127 as the structure directing agent, to synthesize mesoporous carbon-alumina nanocomposites via EISA-induced multi-component co-assembly.

Figure 1 presents the low-angle and wide-angle XRD patterns of OMCA- $x$ nanocomposites. When the alumina content was varied from 11 to $48 \mathrm{wt}$. $\%$, a sharp diffraction peak at around $1.0^{\circ} 2 \theta$, and one or two weak peaks between $1.5^{\circ}$ and $3.0^{\circ} 2 \theta$ were observed, which can be respectively indexed as (100), (110), and (200) reflections of a two-dimensional (2D) hexagonal $(P 6 \mathrm{~mm})$ structure. However, when the alumina content was increased to $53 \mathrm{wt} . \%$, only one broad peak was observed, indicating a less ordered structure. Moreover, there is a slight shift of the peaks towards low angle with increasing the $\mathrm{Al}$ content, implying that the presence of $\mathrm{Al}$ in the nanocomposite reduces framework shrinkage caused by high-temperature pyrolysis. The same phenomenon has been observed in carbon-silica [13] and carbon-titanium oxide [18] nanocomposites. On the other hand, in the wide-angle region, one can only observe two broad peaks at $23.3^{\circ}$ and $42.1^{\circ} 2 \theta$ which are typical of amorphous carbon materials [28]. No reflections corresponding to crystalline alumina phases were observed, indicating that the alumina species in the nanocomposites are either amorphous or highly dispersed in the framework.

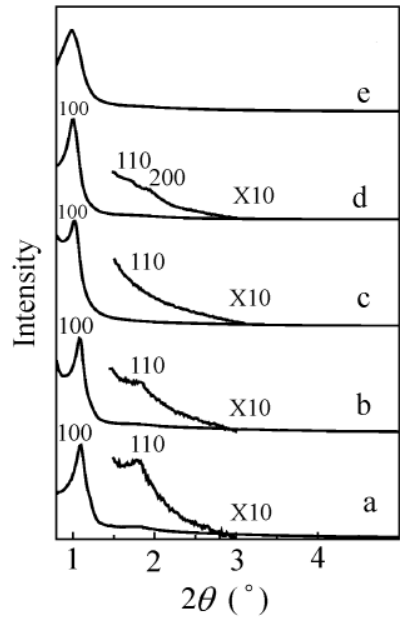

(a)

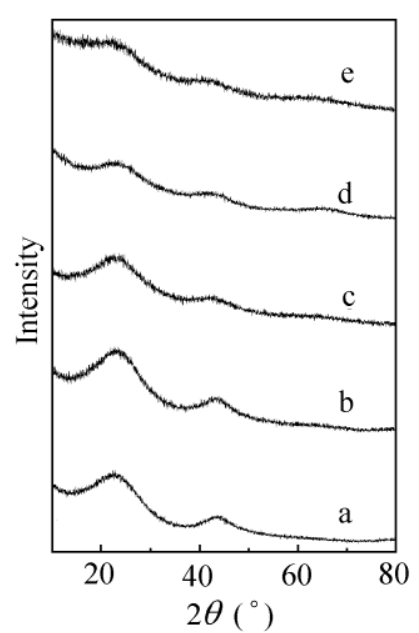

(b)
Figure 1 (a) Low-angle and (b) wide-angle XRD patterns of mesoporous nanocomposites with different alumina contents. a OMCA-11, b OMCA-21, c OMCA-33, d OMCA-48, and e OMCA-53

Figure 2 shows TEM images of the OMCA- $x$ nanocomposites. It is clear that when the $\mathrm{Al}_{2} \mathrm{O}_{3}$ content in the nanocomposites was varied from 11 to $48 \mathrm{wt} . \%$ (Figs. 2(a)-2(d)), highly ordered hexagonal arrangements of pores along the [001] direction and 1D channels along the [110] direction are observed. The TEM images also evidence that our OMCA nanocomposites are thermally stable, with the mesoporous structure being well retained even after pyrolysis at $800{ }^{\circ} \mathrm{C}$. However, when the alumina content in the nanocomposite was increased to $53 \mathrm{wt}$.\%, only wormhole-like pore structures were observed (Fig. 2(e)). This is in agreement with XRD results, and indicates that too much aluminum in the nanocomposites adversely affects the co-assembly of the three components. The synthesis of carbon-alumina nanocomposites is quite different from that of carbon-silica nanocomposites, since the ratio of carbon to silica can be varied from zero to infinity in the latter case. As indicated by Zhao et al. [13], the co-assembly of inorganic and organic precursors into well ordered mesostructures is a very complex process and it requires a suitable balance among the various interactions (inorganic-inorganic, organic-organic, organic-inorganic). In our case, to match closely the hydrolysis-condensation of the aluminum ions with the polymerization of resols and self-assembly of F127, we used citric acid to slow down the rate of hydrolysis-condensation of aluminum ions. 

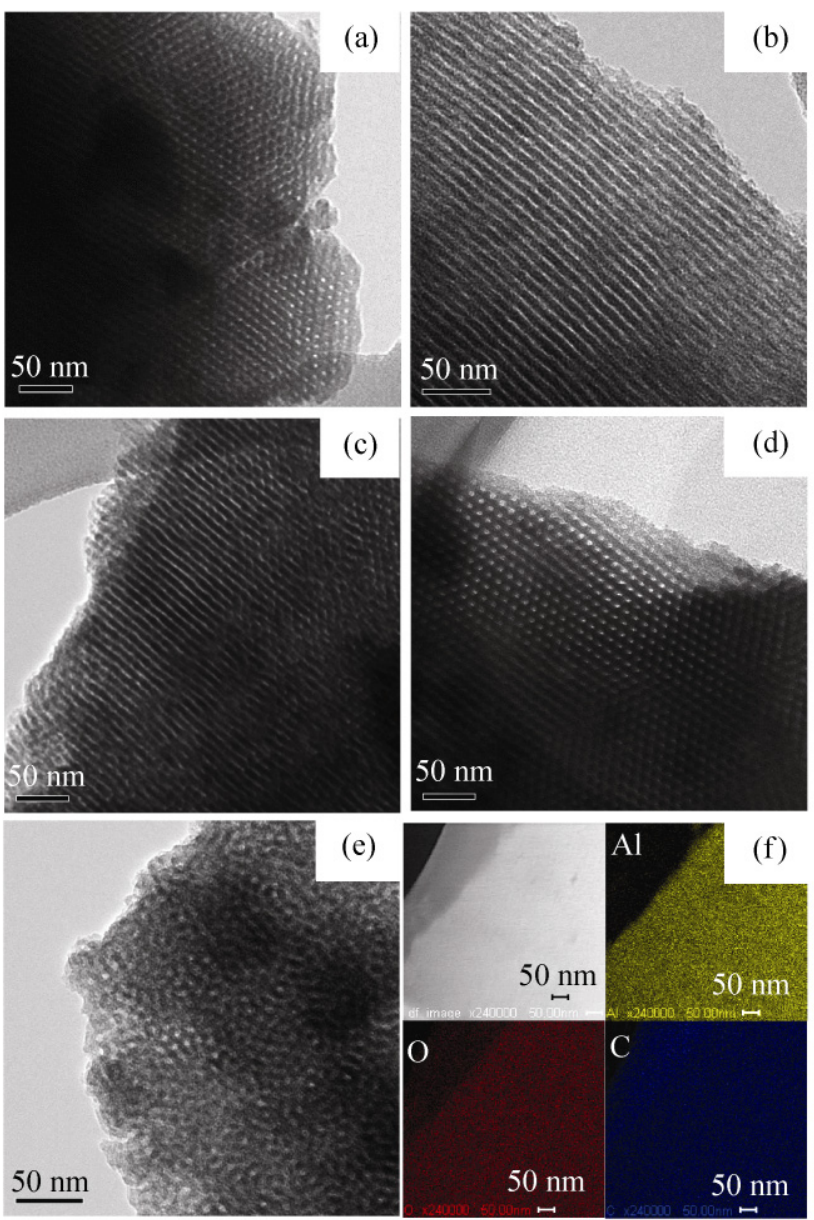

Figure 2 TEM images of mesoporous nanocomposites with different alumina contents. (a) OMCA-11, (b) OMCA-21, (c) OMCA-33, (d) OMCA-48, and (e) OMCA-53. (f) Dark field image and the element mapping of OMCA-48

Therefore, a high aluminum content is accompanied by the introduction of a large amount of citric acid, which may interfere with the self-assembly of F127 and disturb the co-assembly of the different precursors. We found that the synthesis of carbon-alumina nanocomposites is similar to the case of carbontitanium carbide (or oxide) nanocomposites. According to Zhao et al. [21], the highest possible Ti content in the carbon-titanium carbide (or oxide) nanocomposite was $32 \%$, above which the mesostructure collapsed.

To check if the aluminum and carbon are homogeneously dispersed in the walls of the mesoporous nanocomposites, we performed energy-dispersive $X$-ray (EDX) analysis on the OMCA-48 sample in a line-scan mode (see Fig. S-1 in the Electronic Supplementary Material (ESM)) as well as in an elemental mapping mode (Fig. 2(f)). It can be seen that the carbon spectrum is totally consistent with the aluminum spectrum, confirming that the walls are composed of homogeneously dispersed carbon and aluminum species.

The physicochemical properties of our OMCA- $x$ nanocomposites were characterized by $\mathrm{N}_{2}$ adsorptiondesorption measurements. Figure 3 shows the $\mathrm{N}_{2}$ sorption isotherms and the corresponding pore size distributions. All the nanocomposites present type IV isotherms and narrow pore size distributions, characteristic of highly ordered mesoporous materials. The BET surface areas decrease from 491 to $263 \mathrm{~m}^{2} / \mathrm{g}$ with increasing alumina content from 11 to $53 \mathrm{wt} . \%$ (Table 2). This results from the difference in the contributions of the micropores in carbon. It is interesting to note that the mean pore size calculated by the $\mathrm{BJH}$ method using the adsorption branch increases continuously from 2.9 to $5.6 \mathrm{~nm}$ with increasing alumina content from 11 to $53 \mathrm{wt} . \%$, implying the incorporation of alumina into the carbon framework can largely impede the shrinkage of the pores during pyrolysis. We attempted to calcine the OMCA- $x$ in air to remove the carbonaceous material and obtain pure ordered mesoporous alumina (OMA), and etch the alumina by $\mathrm{HF}$ to obtain pure ordered mesoporous carbon (OMC). The results showed that the relative amount of carbon and alumina in the nanocomposite strongly influenced the structural ordering of the resulting pure alumina

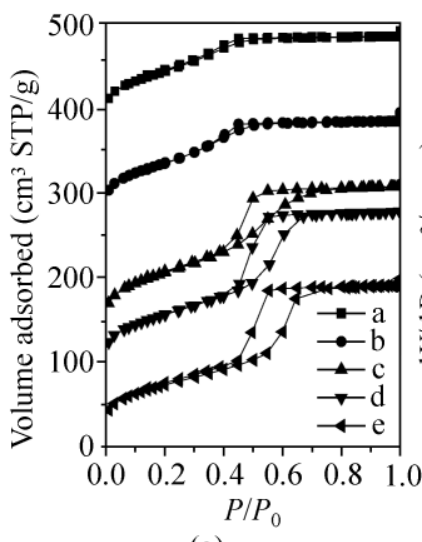

(a)

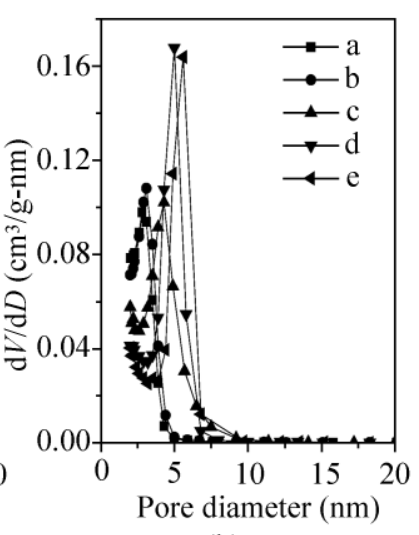

(b)
Figure $3 \mathrm{~N}_{2}$ sorption isotherms (a) and corresponding pore size distributions (b) of mesoporous nanocomposites with different alumina contents. a OMCA-11, b OMCA-21, c OMCA-33, d OMCA-48, and e OMCA-53. The isotherms for OMCA-11, OMCA-21, OMCA-33, and OMCA-48 are offset vertically by 300 , 200,100 , and $50 \mathrm{~cm}^{3} / \mathrm{g}$, respectively

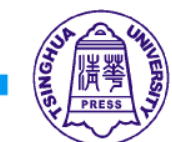

黛 Springer 
Table 2 Textural parameters of mesoporous nanocomposites OMCA $-x$ and the derived OMC- $x$ and OMA- $x$ materials

\begin{tabular}{lcccccc}
\hline \multicolumn{1}{c}{ Sample } & $\begin{array}{c}S_{\mathrm{BET}} \\
\left(\mathrm{m}^{2} \cdot \mathrm{g}^{-1}\right)\end{array}$ & $\begin{array}{c}V_{\mathrm{p}}{ }^{\mathrm{a}} \\
\left(\mathrm{cm}^{3} \cdot \mathrm{g}^{-1}\right)\end{array}$ & $\begin{array}{c}V_{\text {micro }}\left(\mathrm{cm}^{3} \cdot \mathrm{g}^{-1}\right) \\
\left(\mathrm{cm}^{3} \cdot \mathrm{g}^{-1}\right)\end{array}$ & $\begin{array}{c}V_{\text {meso }} \\
\left(\mathrm{cm}^{3} \cdot \mathrm{g}^{-1}\right)\end{array}$ & $\begin{array}{c}a_{0}{ }^{\mathrm{b}} \\
(\mathrm{nm})\end{array}$ \\
\hline OMCA-11 & 491 & 0.29 & 0.10 & 0.17 & 2.9 & 8.1 \\
OMC-11 & 583 & 0.33 & 0.17 & 0.14 & 3.3 & 8.1 \\
OMA-11 & 349 & 0.28 & 0.00 & 0.31 & 3.0 & - \\
OMCA-21 & 466 & 0.30 & 0.09 & 0.20 & 3.1 & 8.2 \\
OMC-21 & 723 & 0.39 & 0.19 & 0.18 & 2.8 & 8.1 \\
OMA-21 & 485 & 0.29 & 0.00 & 0.35 & 2.7 & - \\
OMCA-33 & 422 & 0.26 & 0.07 & 0.19 & 3.2 & 8.5 \\
OMC-33 & 1222 & 0.69 & 0.32 & 0.34 & 3.1 & 8.5 \\
OMA-33 & 434 & 0.30 & 0.00 & 0.35 & 3.3 & 6.6 \\
OMCA-48 & 372 & 0.35 & 0.05 & 0.33 & 5.0 & 10.1 \\
OMC-48 & 1584 & 1.10 & 0.31 & 0.71 & 4.9 & 10.2 \\
OMA-48 & 410 & 0.61 & 0.00 & 0.61 & 5.4 & 8.4 \\
OMCA-53 & 263 & 0.31 & 0.01 & 0.32 & 5.6 & - \\
OMC-53 & 1715 & 1.35 & 0.31 & 0.98 & 5.6 & - \\
OMA-53 & 326 & 0.43 & 0.00 & 0.45 & 5.4 & - \\
\hline
\end{tabular}

${ }^{\mathrm{a}} \mathrm{N}_{2}$ adsorption volume at $P / P_{0}=0.998$

${ }^{\mathrm{b}} a_{0}=2 d(100) / \sqrt{3}$.

and carbon materials. For example, the well-ordered mesoporous nanocomposites OMCA-11 and OMCA-21 could produce OMC materials but failed to produce OMA materials (evidenced by low-angle XRD patterns in Fig. S-2 and TEM images in Fig. S-3 in the ESM), possibly because the small amount of alumina in the nanocomposite could not form a rigid framework after removal of a large amount of carbon. In contrast, nanocomposites OMCA-33 and OMCA-48 which contain comparable amounts of alumina and carbon, produced both highly ordered OMA and OMC materials after removal of carbon or alumina, respectively. To clarify further the effects of removal of carbon or alumina on the mesoporous structure, we take OMCA-48 as an example. As illustrated in Fig. 4, the low-angle XRD patterns of the two samples, OMC-48, and OMA-48, both show one strong peak and two weak but well-resolved peaks, indicating the formation of highly ordered 2D hexagonal mesostructures. Moreover, compared to OMCA-48 and OMC-48, the [100] peak of OMA-48 showed a clear shift towards high angles, and the calculated cell parameter $\left(a_{0}\right)$ was reduced by $16.8 \%$, indicating that a large framework shrinkage occurred during the removal of carbon by calcination in air. The TEM images (Fig. 5) of OMC-48

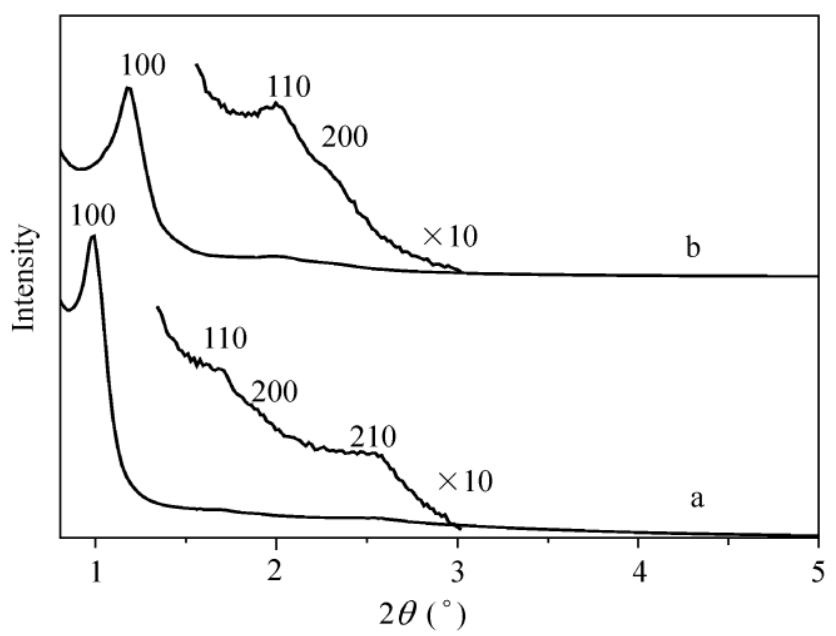

Figure 4 Low-angle XRD patterns of (a) mesoporous carbon OMC-48 and (b) mesoporous alumina OMA-48 which are derived from the nanocomposite OMCA-48

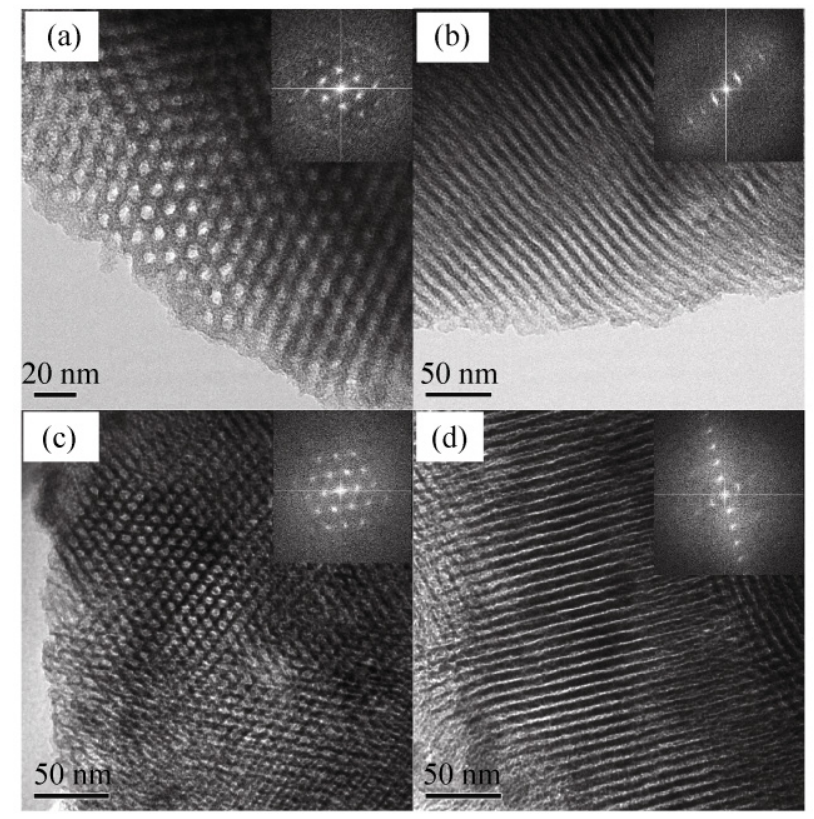

Figure 5 TEM images of mesoporous carbon OMC-48 (a and b) and mesoporous alumina OMA-48 (c and d), viewed from the [001] $(a, c)$ and [110] $(b, d)$ directions. The insets are the corresponding fast Fourier transform (FFT) diffractograms

and OMA-48 along the [110] and [001] directions also show 1D channels and hexagonally arranged pores, in agreement with the XRD results. The $\mathrm{N}_{2}$ sorption isotherms of both OMC-48 and OMA-48 (Fig. S-4 in the ESM) show typical type IV isotherms with welldefined H1 hysteresis loops, also characteristic of mesoporous structures. It should be noted that for 
OMC-48, the volume of adsorbed nitrogen has a large increase at low relative pressures $\left(P / P_{0}=0.01-0.15\right)$, which can be ascribed to the microporous contribution. From the textural parameters listed in Table 2 one can see that the OMA materials derived from OMCA possess large surface areas ranging from 326 to $485 \mathrm{~m}^{2} / \mathrm{g}$, even larger than their precursor materials. From this point of view, our new nanomaterials OMCA can be regarded as an alternative and good precursor for preparing highly ordered and large-surface-area mesoporous alumina. The OMC materials derived from the OMCA materials exhibit large surface areas up to $1715 \mathrm{~m}^{2} / \mathrm{g}$, and bimodal pore size distributions (Fig. S-4 in the ESM), similar to those obtained from carbonsilica nanocomposites reported by Zhao et al. [13].

As evidenced by wide-angle XRD and TEM measurements, the aluminium species in the nanocomposites obtained by pyrolysis at $800{ }^{\circ} \mathrm{C}$ is amorphous alumina or highly dispersed in the nanocomposites. In an attempt to obtain nanocomposites containing carbon and crystalline alumina, we elevated the pyrolysis temperature to 900,1000 , and $1100{ }^{\circ} \mathrm{C}$. As shown in Fig. 6, the samples prepared at $900{ }^{\circ} \mathrm{C}$ and $1000{ }^{\circ} \mathrm{C}$ have almost the same wide-angle XRD patterns as that prepared at $800{ }^{\circ} \mathrm{C}$, revealing the amorphous nature of alumina. Yet the mesoporous structure was well retained at or below $1000{ }^{\circ} \mathrm{C}$. In contrast, for the sample prepared at $1100{ }^{\circ} \mathrm{C}$, well-crystallized $\gamma-\mathrm{Al}_{2} \mathrm{O}_{3}$ was formed, as evidenced by the characteristic [440], [400], [222], [311], [220], and [111] reflections. Meanwhile,

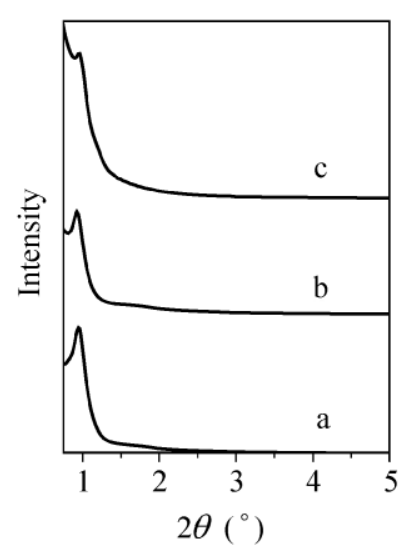

(a)

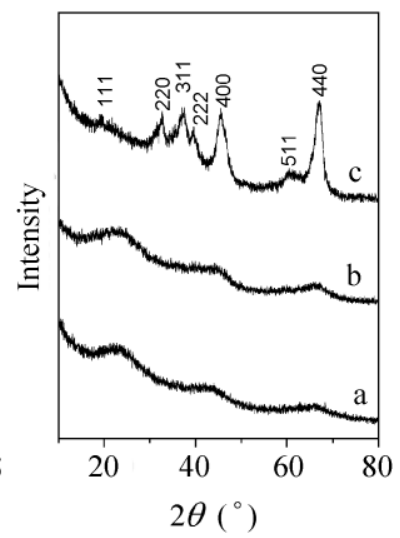

(b)
Figure 6 Low-angle (a) and wide-angle (b) XRD patterns of OMCA-48 nanocomposites which were obtained by pyrolysis at a 900 , b 1000 , and c $1100{ }^{\circ} \mathrm{C}$. the TEM images (Fig. S-5 in the ESM) reveal that large domains of the mesostructure collapsed. This result indicates that although the walls of the OMCA nanocomposite are composed of continuous carbon and alumina, aggregation of the highly dispersed alumina particles and their subsequent crystallization will inevitably destroy the mesostructure. According to Yan et al. [31], ordered mesoporous $\gamma-\mathrm{Al}_{2} \mathrm{O}_{3}$ with crystalline walls can be prepared by heat treatment at $800-1000{ }^{\circ} \mathrm{C}$, whilst calcination at $1100{ }^{\circ} \mathrm{C}$ promotes the transformation of $\gamma-\mathrm{Al}_{2} \mathrm{O}_{3}$ into $\alpha-\mathrm{Al}_{2} \mathrm{O}_{3}$. However, in our case, pyrolysis at $1100{ }^{\circ} \mathrm{C}$ still yielded a $\gamma-\mathrm{Al}_{2} \mathrm{O}_{3}$ phase. Clearly, the unique structure of the carbon-alumina composite significantly inhibits the aggregation and crystallization of alumina.

The above-prepared OMCA nanocomposites, not only possessing highly ordered mesoporous structures and large surface areas, but also with tunable compositions of the walls, are expected to provide many more opportunities than traditional single component materials for tuning the activities and selectivities when they are used as supports for metal catalysts. In the present work, $\mathrm{Pt}$ was chosen as the metal to be dispersed on the nanocomposites and the resultant catalysts were evaluated for cellulose conversion in hot water and under $\mathrm{H}_{2}$ pressure. Considering that the nature and composition of the support often greatly affect the catalytic performance of the metal particles on it, we compared the catalytic performance of Pt/OMCA-48, Pt/OMC-48, and Pt/OMA-48 in the selective transformation of cellulose to hexitols. The catalytic results are shown in Table 3 and Fig. S-6 in the ESM. It is interesting to note that the nanocompositesupported $\mathrm{Pt}$ catalyst Pt/OMCA-48 gave the best performance, with a yield of hexitols of up to $47.5 \%$ with a mass ratio of sorbitol to mannitol of ca 3.0. The conversion of cellulose reached nearly $100 \%$. With the Pt/OMA-48 catalyst, the yield of hexitols was $31.0 \%$, the same as that reported by Fukuoka et al. for a commercial $\gamma-\mathrm{Al}_{2} \mathrm{O}_{3}$-supported Pt catalyst [1], although our OMA has a different pore structure from that of the commercial $\gamma-\mathrm{Al}_{2} \mathrm{O}_{3}$. On the other hand, a hexitol yield of only $26.3 \%$ was obtained with the Pt/OMC- 48 catalyst, although the yield of ethylene glycol was increased to $14.7 \%$. It should also be pointed out that the conversion of cellulose with the $\mathrm{Pt} / \mathrm{OMC}-48$ 
Table 3 Degree of cellulose conversion and yield of polyols over Pt catalysts supported on different supports ${ }^{\text {a }}$

\begin{tabular}{|c|c|c|c|c|c|c|}
\hline \multirow{2}{*}{ Catalyst } & \multirow{2}{*}{$\begin{array}{l}\mathrm{H}_{2} \text { uptake } \\
\left(\mu \mathrm{mol} \cdot \mathrm{g}^{-1}\right)\end{array}$} & \multicolumn{4}{|c|}{ Yield $^{\mathrm{b}}(\%)$} & \multirow{2}{*}{${ }_{\mathrm{e}}{ }^{\text {Conv. }}{ }^{\mathrm{c}}(\%)$} \\
\hline & & $\mathrm{EG}^{\mathrm{d}}$ & Sorbitol & Mannitc & $1,2-\mathrm{PG}^{\mathrm{e}}$ & \\
\hline $\mathrm{Pt} / \mathrm{OMCA}-48$ & 97.3 & 8.4 & 35.6 & 11.9 & 2.9 & 99 \\
\hline $\mathrm{Pt} / \mathrm{OMC}-48$ & 12.9 & 14.7 & 20.0 & 6.3 & 5.9 & 85 \\
\hline $\mathrm{Pt} / \mathrm{OMA}-48$ & 121.8 & 8.0 & 20.7 & 10.3 & 3.6 & 100 \\
\hline \multicolumn{7}{|c|}{$\begin{array}{l}{ }^{\mathrm{a}} \text { Reaction conditions: } 0.15 \mathrm{~g} \text { catalyst, } 0.5 \mathrm{~g} \text { cellulose, } 50 \mathrm{~g} \mathrm{H}_{2} \mathrm{O}, 245^{\circ} \mathrm{C}, 6 \mathrm{MPa} \\
\mathrm{H}_{2} \text { for } 30 \mathrm{~min} \text {. }\end{array}$} \\
\hline \multicolumn{7}{|c|}{$\begin{array}{l}{ }^{\mathrm{b}} \text { The yield of polyols was calculated using the equation: yield }(\%)=\left(W_{\text {polyol }} /\right. \\
\left.W_{\text {cellulose }}\right) \times 100 \% \text {. }\end{array}$} \\
\hline \multicolumn{7}{|c|}{$\begin{array}{l}\text { c The conversion was calculated by the mass difference of cellulose before and } \\
\text { after reaction. }\end{array}$} \\
\hline \multicolumn{7}{|c|}{${ }^{\mathrm{d}} \mathrm{EG}$ is ethylene glycol. } \\
\hline & & & & & & \\
\hline
\end{tabular}

catalyst was only $85 \%$, in contrast to conversions of nearly $100 \%$ observed with the other two catalysts. The nanocomposite OMCA-48 clearly demonstrates great advantages over its single-component counterparts when acting as the Pt catalyst support for cellulose conversion into hexitols. To reveal the underlying reason, we further characterized the three catalysts by TEM and chemisorption techniques. As shown in Fig. 7 , the $\mathrm{Pt}$ particles in the $\mathrm{Pt} / \mathrm{OMCA}-48$ are very small, around 1-2 nm. In contrast, Pt particles with an average size of $\sim 5 \mathrm{~nm}$ are clearly visible on the Pt/OMC-48 catalyst, while no particles are visible on the Pt/OMA-48 catalyst. $\mathrm{H}_{2}$-chemisorption results show that the $\mathrm{H}_{2}$ uptakes on the three catalysts follow the order Pt/OMA-48 > Pt/OMCA-48 > Pt/OMC-48, which correlates well with the opposite order of the $\mathrm{Pt}$ particle size of the three catalysts. It is therefore reasonable to conclude that the appropriate $\mathrm{Pt}$ particle size on the OMCA nanocomposite support, controlled by the medium-strength metal-support interaction, is responsible for the superior performance of the Pt/OMCA. Very recently, Wan et al. [33] reported that an ordered mesoporous carbon-silica nanocomposite exhibited a superior activity for the coupling reaction of chlorobenzene in aqueous media when $\mathrm{Pd}$ was supported on it. They also suggested that the nanocomposite improved the catalytic activity of $\mathrm{Pd}$ by affecting the Pd particle size, in agreement with our conclusion. Further investigations of the catalytic performance of different nanocomposite (OMCA- $x$ ) supported Pt catalysts are underway.
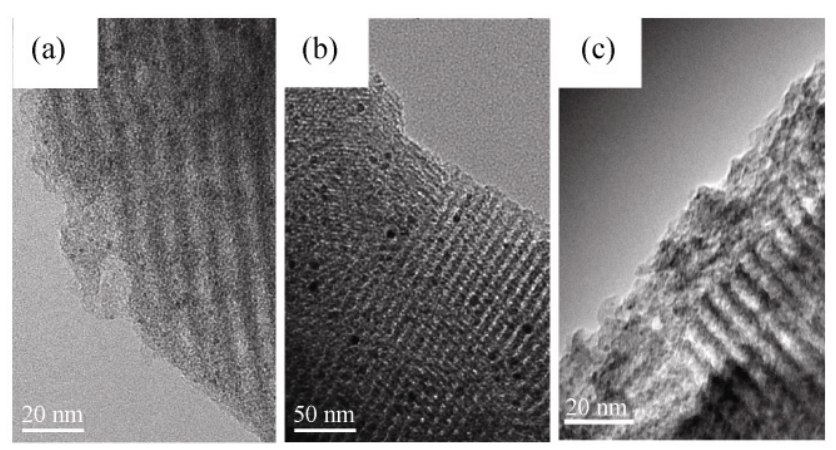

Figure 7 TEM images of (a) 4\% Pt/OMCA-48, (b) 4\% Pt/OMC48 , and (c) $4 \%$ Pt/OMA-48

\section{Conclusions}

We have successfully fabricated carbon-alumina nanocomposites with highly ordered mesoporous structures via co-assembly of resol, alumina sol, and triblock copolymer F127. The framework walls are composed of continuous carbon and highly dispersed amorphous alumina, and the alumina content can be continuously tuned from 11 to $48 \mathrm{wt}$.\% while maintaining the highly ordered mesoporous structure. The carbon-alumina nanocomposites show good thermal stability below $1000{ }^{\circ} \mathrm{C}$; at higher temperatures, crystallization of alumina to the $\gamma$-phase takes place, leading to the partial collapse of the mesostructure. Our new carbonalumina nanocomposites exhibited superior performance to the individual single components when used as supports for Pt catalysts. The Pt/OMCA- 48 nanocomposite could convert cellulose efficiently into hexitols, with a yield as high as $47.5 \%$. It is expected that the unique and tunable properties (tunable hydrophobicity and hydrophilicity, adjustable metalsupport interaction, and good hydrothermal stability) of carbon-alumina nanocomposites will find wide applications in adsorption, catalysis, energy storage, and other fields. The successful synthesis of these carbon-alumina nanocomposites again demonstrates the power of the multi-component co-assembly strategy in fabricating advanced and multifunctional materials.

\section{Acknowledgements}

Support from the Natural Science Foundation of China (NSFC Nos. 20773124 and 20773122) and from the National Basic Research Program of China (No. 
2009CB226102) is gratefully acknowledged. The authors thank Na Ji and Dr. Mingyuan Zheng for assistance with catalytic reactions.

Electronic Supplementary Material: Supplementary material (further details of $\mathrm{N}_{2}$ sorption isotherms, XRD patterns, TEM images, and energy dispersive (EDS) spectra) is available in the online version of this article at http://dx.doi.org/10.1007/s12274-010-0038-0 and is accessible free of charge.

Open Access: This article is distributed under the terms of the Creative Commons Attribution Noncommercial License which permits any noncommercial use, distribution, and reproduction in any medium, provided the original author(s) and source are credited.

\section{References}

[1] Fukuoka, A.; Dhepe, P. L. Catalytic conversion of cellulose into sugar alcohols. Angew. Chem. Int. Ed. 2006, 45, 51615163.

[2] Luo, C.; Wang, S.; Liu, H. C. Cellulose conversion into polyols catalyzed by reversibly formed acids and supported ruthenium clusters in hot water. Angew. Chem. Int. Ed. 2007, 46, 7636-7639.

[3] Ji, N.; Zhang, T.; Zheng, M. Y.; Wang, A. Q.; Wang, H.; Wang, X. D.; Chen, J. G. G. Direct catalytic conversion of cellulose into ethylene glycol using nickel-promoted tungsten carbide catalysts. Angew. Chem. Int. Ed. 2008, 47, 8510-8513.

[4] Ji, N.; Zhang, T.; Zheng, M. Y.; Wang, A. Q.; Wang, H.; Wang, X. D.; Shu, Y. Y.; Stottlemyer, A. L.; Chen, J. G. Catalytic conversion of cellulose into ethylene glycol over supported carbide catalysts. Catal. Today 2009, 147, 77-85.

[5] Zhang, Y. H.; Wang, A. Q.; Zhang, T. A new 3D mesoporous carbon replicated from commercial silica as a catalyst support for direct conversion of cellulose into ethylene glycol. Chem. Commun. 2010, 46, 862-864.

[6] Zheng, M. Y.; Wang, A. Q.; Ji, N.; Pang, J. F.; Wang, X. D.; Zhang, T. Transition metal-tungsten bimetallic catalysts for the conversion of cellulose into ethylene glycol. ChemSusChem 2010, 3, 63-66.

[7] Augustin, R. L. Heterogeneous catalysis for the synthetic chemist; Marcel Dekker, Inc.: New York, 1995.

[8] Xia, W. S.; Wan, H. L.; Chen, Y. Cluster model study on the surface interactions of $\gamma$-alumina-supported metal oxides. $J$. Mol. Catal. A 1999, 138, 185-195.

[9] Abasov, S. I.; Borovkov, V. Y.; Kazansky, V. B. Infrared and adsorption study of strong metal - support interaction in diluted platinum - alumina catalysts. Catal. Lett. 1992, 15, 269-274.

[10] Li, D.; Zhou, H.; Honma, I. Design and synthesis of selfordered mesoporous nanocomposite through controlled in situ crystallization. Nat. Mater. 2004, 3, 65-72.

[11] Lu, A. H.; Li, W.; Hou, Z.; Schüth, F. Molecular level dispersed Pd clusters in the carbon walls of ordered mesoporous carbon as a highly selective alcohol oxidation catalyst. Chem. Commun. 2007, 1038-1040.

[12] Liang, C.; Dudney, N. J.; Howe J. Y. Hierarchically structured sulfur carbon nanocomposite material for high-energy lithium battery. Chem. Mater. 2009, 21, 4724-4730.

[13] Liu, R. L.; Shi, Y. F.; Wan, Y.; Meng, Y.; Zhang, F. Q.; Gu, D.; Chen, Z. X.; Tu, B.; Zhao, D. Y. Triconstituent coassembly to ordered mesostructured polymer-silica and carbon-silica nanocomposites and large-pore mesoporous carbons with high surface areas. J. Am. Chem. Soc. 2006, 128, 11652-11662.

[14] Lin, H. P.; Chang-Chien, C. Y.; Tang, C. Y.; Lin, C. Y. Synthesis of $p 6 \mathrm{~mm}$ hexagonal mesoporous carbons and silicas using Pluronic F127-PF resin polymer blends. Micropor. Mesopor. Mater. 2006, 93, 344-348.

[15] Hu, Q. Y.; Kou, R.; Pang, J. B.; Ward, T. L.; Cai, M.; Yang, Z. Z.; Lu, Y. F.; Tang, J. Mesoporous carbon/silica nanocomposite through multi-component assembly. Chem. Commun. 2007, 601-603.

[16] Gorka, J.; Jaroniec, M. Incorporation of inorganic nanoparticles into mesoporous carbons synthesized by soft templating. J. Phys. Chem. C 2008, 112, 11657-11660.

[17] Jaroniec, M.; Gorka, J.; Choma, J.; Zawislak, A. Synthesis and properties of mesoporous carbons with high loadings of inorganic species. Carbon 2009, 47, 3034-3040.

[18] Liu, R.; Ren, Y.; Shi, Y.; Zhang, F.; Zhang, L.; Tu, B.; Zhao, D. Controlled synthesis of ordered mesoporous $\mathrm{C}-\mathrm{TiO}_{2}$ nanocomposites with crystalline titania frameworks from organic-inorganic-amphiphilic coassembly. Chem. Mater. 2008, 20, 1140-1146.

[19] Choma, J.; Zubrowska, A.; Górka, J.; Jaroniec, M. Softtemplating synthesis of nanoporous carbons with incorporated alumina nanoparticles. Ann. UMCS 2009, 64, 259-272.

[20] Zhai, Y.; Dou, Y.; Liu, X.; Tu, B.; Zhao, D. Y. One-pot synthesis of magnetically separable ordered mesoporous carbon. J. Mater. Chem. 2009, 19, 3292-3300.

[21] Yu, T.; Deng, Y. H.; Wang, L.; Liu, R. L.; Zhang, L. J.; Tu, B.; Zhao, D. Y. Ordered mesoporous nanocrystalline titanium-carbide/carbon composites from in situ carbothermal reduction. Adv. Mater. 2007, 19, 2301-2306.

[22] Wang, H.; Wang, A. Q.; Wang, X. D.; Zhang, T. One-pot 
synthesized MoC imbedded in ordered mesoporous carbon as a catalyst for $\mathrm{N}_{2} \mathrm{H}_{4}$ decomposition. Chem. Commun. 2008, 2565-2567.

[23] Zhou, J. H.; He, J. P.; Wang, T.; Sun, D.; Zhao, G. W.; Chen, X.; Wang, D. J.; Di, Z. Y. $\mathrm{NiCl}_{2}$ assisted synthesis of ordered mesoporous carbon and a new strategy for a binary catalyst. J. Mater. Chem. 2008, 18, 5776-5781.

[24] Yao, J.; Li, L.; Song, H.; Liu, C.; Chen, X. Synthesis of magnetically separable ordered mesoporous carbons from F127/[Ni( $\left.\left.\mathrm{H}_{2} \mathrm{O}\right)_{6}\right]\left(\mathrm{NO}_{3}\right)_{2} /$ resorcinol-formaldehyde composites. Carbon 2009, 47, 436-444.

[25] Wang, X.; Dai, S. A simple method to ordered mesoporous carbons containing nickel nanoparticles. Adsorption 2009, $15,138-144$.

[26] Ji, Z. H.; Liang, S. G.; Jiang, Y. B.; Li, H.; Liu, Z. M.; Zhao, $\mathrm{T}$. Synthesis and characterization of ruthenium-containing ordered mesoporous carbon with high specific surface area. Carbon 2009, 47, 2194-2199.

[27] Li, J. S.; Gu, J.; Li, H. J.; Liang, Y.; Hao, Y. X.; Sun, X. Y.; Wang, L. J. Synthesis of highly ordered Fe-containing mesoporous carbon materials using soft templating routes. Micropor. Mesopor. Mater. 2010, 128, 144-149.

[28] Gao, P.; Wang, A.; Wang, X.; Zhang, T. Synthesis of highly ordered Ir-containing mesoporous carbon materials by organic-organic self-assembly. Chem. Mater. 2008, 20, 1881-1888.

[29] Gao, P.; Wang, A. W.; Wang, X. D.; Zhang, T. Synthesis and catalytic performance of highly ordered Ru-containing mesoporous carbons for hydrogenation of cinnamaldehyde. Catal. Lett. 2008, 125, 289-295.

[30] Liu, Q.; Wang, A.; Wang, X.; Zhang, T. Mesoporous $\gamma$-alumina synthesized by hydro-carboxylic acid as structuredirecting agent. Micropor. Mesopor. Mater. 2006, 92, 10-21.

[31] Yuan, Q.; Yin, A. X.; Luo, C.; Sun, L. D.; Zhang, Y. W.; Duan, W. T.; Liu, H. C.; Yan, C. H. Facile synthesis for ordered mesoporous $\gamma$-aluminas with high thermal stability. J. Am. Chem. Soc. 2008, 130, 3465-3472.

[32] Meng, Y.; Gu, D.; Zhang, F. Q.; Shi, Y. F.; Yang, H. F.; Li, Z.; Yu, C. Z.; Tu, B.; Zhao, D. Y. Ordered mesoporous polymers and homologous carbon frameworks: Amphiphilic surfactant templating and direct transformation. Angew. Chem. Int. Ed. 2005, 44, 7053-7059.

[33] Wan, Y.; Wang, H.; Zhao, Q.; Klingstedt, M.; Terasaki, O.; Zhao, D. Ordered mesoporous Pd/silica-carbon as a highly active heterogeneous catalyst for coupling reaction of chlorobenzene in aqueous media. J. Am. Chem. Soc. 2009, $131,4541-4550$. 